\title{
Severe hyponatremia with seizures and confirmed mild brain edema by hysteroscopic myomectomy: a case report
}

\author{
Haruko Okazaki ${ }^{1 \dagger}$, Norikazu Miura ${ }^{1 \dagger}$, Yuki Kashima ${ }^{1}$, Ryoichi Miyashita², Katsunori Oe ${ }^{1}$, Keiko Kawakami ${ }^{3}$, \\ Tetsuya Ishikawa ${ }^{3}$ and Kenichi Masui ${ }^{1 *}$ (i)
}

\begin{abstract}
Background: Hyponatremia can be developed during hysteroscopic surgery with electrolyte-free irrigation fluid. We experienced severe hyponatremia with postoperative seizures and confirmed mild brain edema.

Case presentation: A quadragenarian female patient underwent a 2-h hysteroscopic myomectomy with electrolyte-free fluid for uterine distension under general anesthesia. Plasma sodium level of $84.1 \mathrm{mmol} / \mathrm{L} 100 \mathrm{~min}$ after the start of surgery indicated excessive absorption of the irrigation fluid. Acute severe hyponatremia was diagnosed with significant edema in the conjunctiva, lip, and extremities. She was treated with a continuous infusion of hypertonic saline. However, seizures and cerebral edema developed $7 \mathrm{~h}$ later. The patient recovered without neurological deficits at postoperative day 2.

Conclusion: The electrolyte-free irrigation fluid can be absorbed rapidly during hysteroscopic surgery. Its interruption with hyponatremia should be considered against prolonged surgery. Especially under general anesthesia, caution should be exercised because the typical symptoms of hyponatremia such as nausea and confusion are blinded.
\end{abstract}

Keywords: Severe hyponatremia, Hysteroscopic surgery, Brain edema, Seizures, Neurological deficit, Electrolyte-free irrigation fluid

\section{Background}

Hyponatremia is a severe complication of hysteroscopic myomectomy, caused by the absorption of fluid media used for uterine distension via damaged blood vessel and myometrium [1-7]. Absorption of an electrolyte-free fluid media can decrease the plasma colloid osmotic pressure, which results in fluid movement from intravascular to extravascular space. These changes can cause low arterial pressure, circulatory failure, cerebral edema, convulsions, and even death by osmotic demyelination [8]. Here, we report a case of severe hyponatremia developed during a hysteroscopic surgery with postoperative seizures and

\footnotetext{
* Correspondence: kenichi@masuinet.com

${ }^{+}$Haruko Okazaki and Norikazu Miura contributed equally to this work. 'Department of Anesthesiology, Showa University School of Medicine, 1-5-8 Hatanodai, Shinagawa, Tokyo 142-8666, Japan

Full list of author information is available at the end of the article
}

confirmed mild brain edema, and fully recovered on postoperative day 2.

\section{Case presentation}

A written patient consent was obtained for this report. A quadragenarian female patient (height $151 \mathrm{~cm}$, body weight $37 \mathrm{~kg}$ ) was scheduled for a hysteroscopic myomectomy under general anesthesia. Her chief complaint was hypermenorrhea. Preoperative ultrasound revealed a 3.6$\mathrm{cm}$ submucous uterine myoma which protruded into the uterine cavity (protrusion ratio: 60-70\%). Gonadotropinreleasing hormone therapy was initiated 3 months prior to the operation to improve anemia and shrink the myoma. Her preoperative laboratory tests were normal except the serum bilirubin level of $1.3 \mathrm{mg} / \mathrm{dL}$. Electrocardiogram, non-invasive blood pressure, and pulse oximetry were applied for intra-anesthesia monitoring. Immediately before 
the anesthesia induction, the vital signs were as follows: blood pressure, $114 / 80 \mathrm{mmHg}$; heart rate, $82 \mathrm{bpm}$; and $\mathrm{SpO}_{2}, 100 \%\left(\mathrm{FiO}_{2}=0.21\right)$. General anesthesia was induced with fentanyl, propofol, and rocuronium, followed by tracheal intubation and maintained with desflurane and remifentanil. The urinary catheter was not inserted as the estimated operation time was $1 \mathrm{~h}$. Electrolyte-free 3\% dsorbitol solution (Uromatic $\mathrm{S}^{\bullet}, 165 \mathrm{mOsm} / \mathrm{L}$, Baxter Limited, Tokyo, Japan) was used for monopolar electrosurgery. The patient was placed in a lithotomy position. The solution bag was placed at approximately $100 \mathrm{~cm}$ height from the surgical table without any additional pressure applied to the bag. The difference between the fluid inflow and outflow increased over time. During the latter half of the surgery, a substantial spillage was observed on the floor. A mild decrease in blood pressure was observed throughout the surgery. Approximately $100 \mathrm{~min}$ after the start of surgery, the plasma sodium level was estimated as $84.1 \mathrm{mmol} / \mathrm{L}$. At the end of the 123-min surgery, the difference between the inflow $(21 \mathrm{~L})$ and the collected outflow $(14 \mathrm{~L})$ was $7 \mathrm{~L}$ excluding the spillage. At this time, the vital signs were as follows: blood pressure, $80 / 34 \mathrm{mmHg}$; heart rate, $60 \mathrm{bpm}, \mathrm{SpO}_{2}, 99 \%\left(\mathrm{FiO}_{2}=0.45\right)$. Premature ventricular contractions were observed 5 to 10 times per minute. The intravenous fluid infused was $780 \mathrm{~mL}$ in total. The urinary catheter was inserted due to prolonged surgical time. Immediately, $1000 \mathrm{~mL}$ of urine was excreted. After the drapes were removed, distention of the lower abdomen and navel was noticed. No abdominal fluid wave on palpitation, and no findings of intraperitoneal fluid retention by an abdominal ultrasound exam were observed. However, there were significant edemas in the conjunctiva, lip, and fingers (Fig. 1). Arterial blood gas test revealed severe hyponatremia and acidemia $(\mathrm{pH} 7.188$; plasma sodium level $88.1 \mathrm{mmol} / \mathrm{L}$; partial pressure of carbon dioxide $41.7 \mathrm{mmHg}$; partial pressure of oxygen 147.7 $\mathrm{mmHg}$ ). Chest X-ray suggested mild pulmonary edema (Fig. 1). With these findings, we diagnosed acute hyponatremia due to water intoxication. One hour after the immediate administration of $20 \mathrm{mg}$ furosemide, an additional $1000 \mathrm{~mL}$ of urine was excreted. However, the second arterial blood gas test still indicated severe hyponatremia (plasma sodium level $90.8 \mathrm{mmol} / \mathrm{L}$ ). She was admitted to the intensive care unit (ICU) under sedation and mechanical ventilation with tracheal intubation.

The details of correctional treatment, and transition of plasma sodium level and urine output are described in Fig. 2. Sedation was maintained with propofol. During the first $4 \mathrm{~h}$, acetate Ringer solution and an additional $20 \mathrm{mg}$ furosemide were given. Although the diuresis over $100 \mathrm{~mL} / \mathrm{h}$ was maintained, metabolic acidosis, high lactate level, and low blood pressure persisted. After $6 \mathrm{~h}$ from the ICU admission, the coexistence of intravascular dehydration was diagnosed by increased lactic level and progression of metabolic acidosis. Accordingly, 5\% albumin followed by blood transfusion was administered, and continuous infusion of noradrenaline was initiated at $0.05 \mu \mathrm{g} / \mathrm{kg} / \mathrm{min}$. For sodium correction, continuous administration of $1.5 \%$ saline was also initiated. The patient developed a few short seizures at $7 \mathrm{~h}$ after ICU

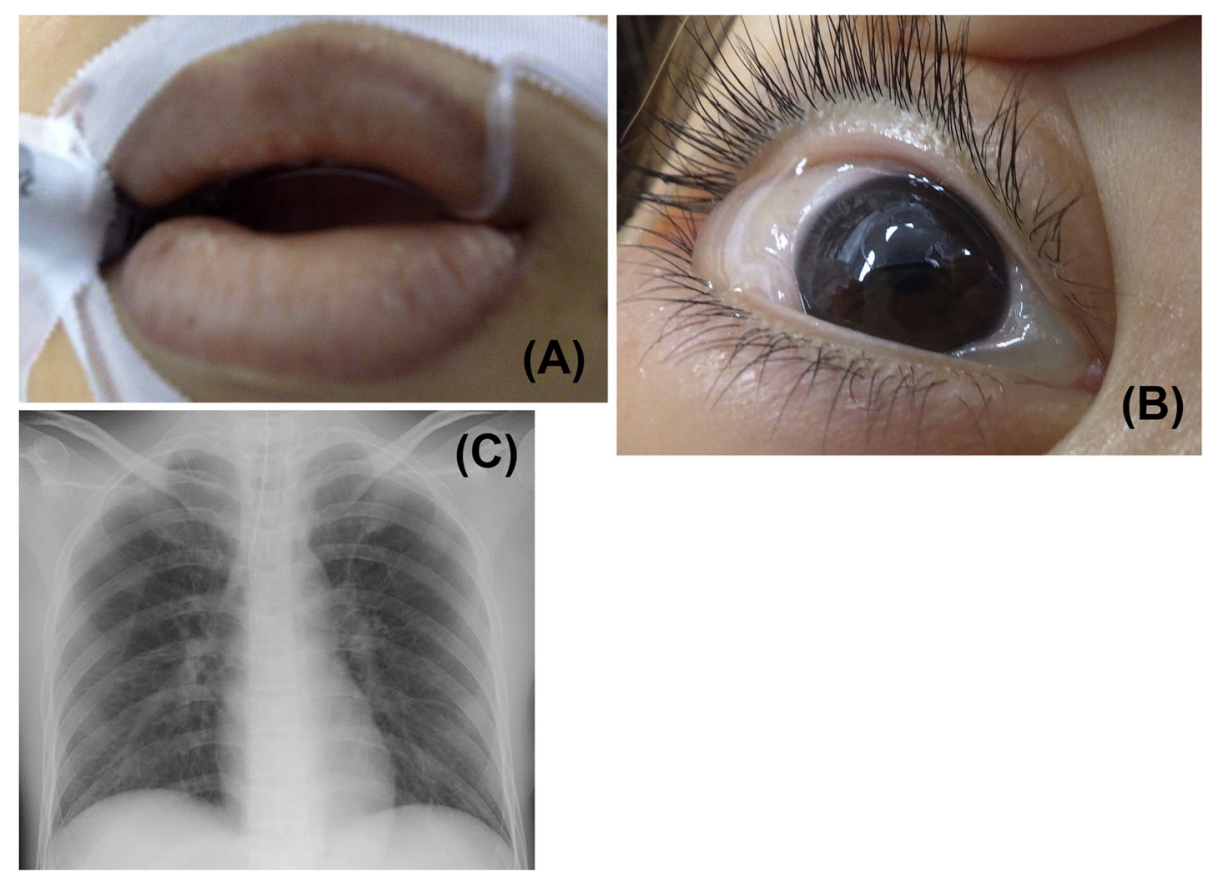

Fig. 1 Edema of lips (a) and conjunctiva (b), and chest X-ray (c) at the end of the operation 

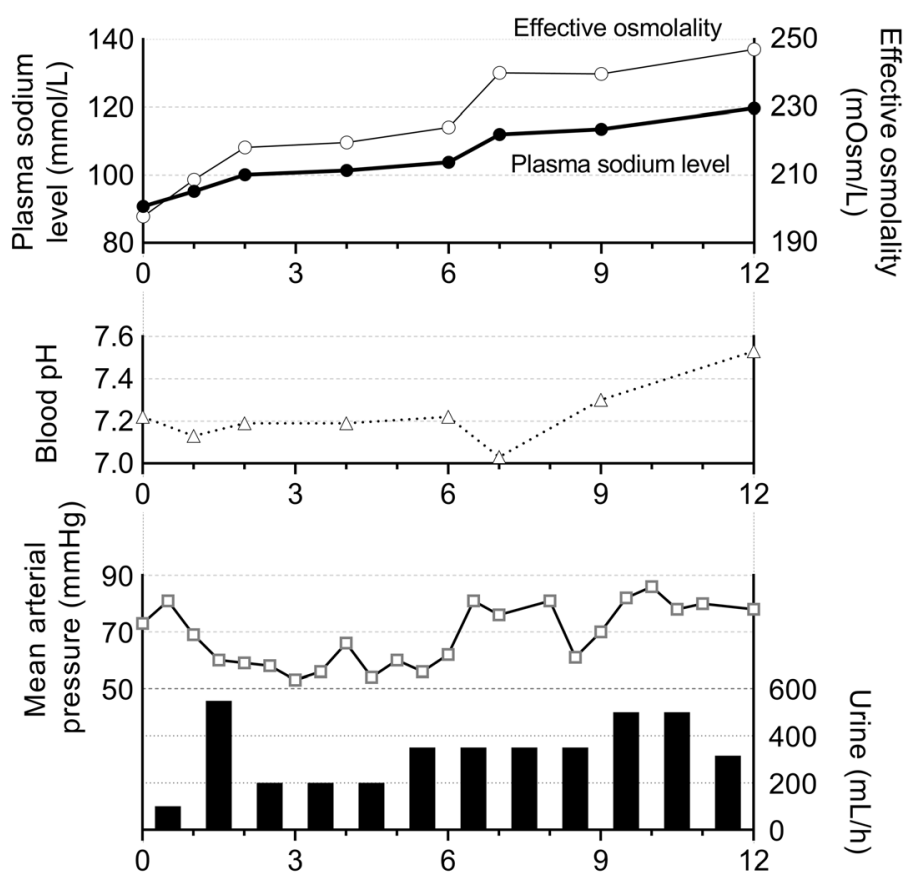

Time since ICU admission (h)

\section{Treatments}

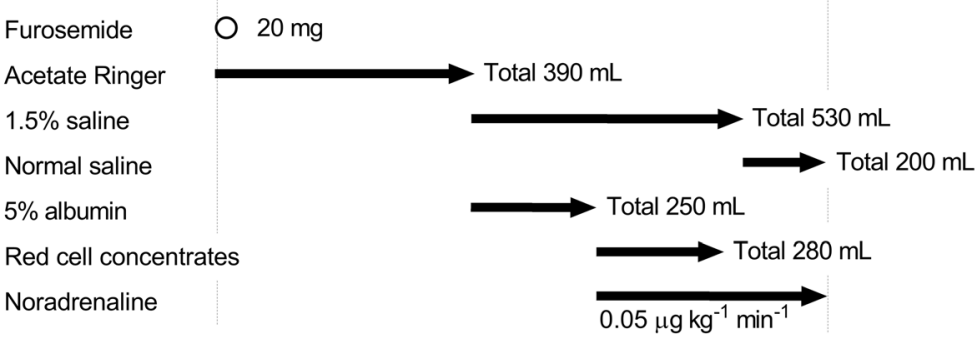

Fig. 2 Time courses of plasma sodium level, effective osmolality, blood pH, mean arterial pressure, urine output, and treatments for hyponatremia in intensive care unit. Each symbol indicates each measurement and each black bar shows hourly urine output. For the treatments, each arrow indicates the duration of the treatment, and open circle indicates the time of furosemide administration

admission and recovered spontaneously. A head computed tomography taken immediately after the attack showed mild cerebral edema (Fig. 3). At this time, the plasma sodium level was $112.0 \mathrm{mmol} / \mathrm{L}$ with metabolic acidosis. Treatments of $1.5 \%$ saline and noradrenaline infusion were continued until $12 \mathrm{~h}$ since the ICU admission. Three hours later ( $15 \mathrm{~h}$ after the ICU admission), the patient was extubated under light sedation with propofol after confirming the improvement of the electrolyte balance (plasma sodium level $125.6 \mathrm{mmol} / \mathrm{L}$ ), blood pressure stabilized, and the frequency of premature ventricular contractions decreased. Glasgow coma scale was E3V1M4 immediately after extubation. A further $3 \mathrm{~h}$ later, no abnormalities were found in cerebral magnetic resonance imaging. At $7 \mathrm{~h}$ later after extubation, Glasgow coma scale was E3V5M6. On the second postoperative day, her consciousness fully recovered. She was released from the hospital on the sixth postoperative day, following a physical examination by a neurologist and a second cerebral magnetic resonance imaging, which revealed no neurological deficits.

\section{Discussion}

In this case, severe hyponatremia occurred during a 2-h hysteroscopic myomectomy with electrolyte-free solution. Although a seizure attack and mild brain edema occurred, the patient fully recovered on the second postoperative day.

Hysteroscopic surgery is generally less invasive than laparoscopic or open surgery when the patient selection is appropriate. As this case had $3.6 \mathrm{~cm}$ leiomyoma, smaller than $4-5 \mathrm{~cm}$, the indication was applicable [9]. However, excessive fluid absorption can be a lifethreatening complication in a hysteroscopic surgery. A 


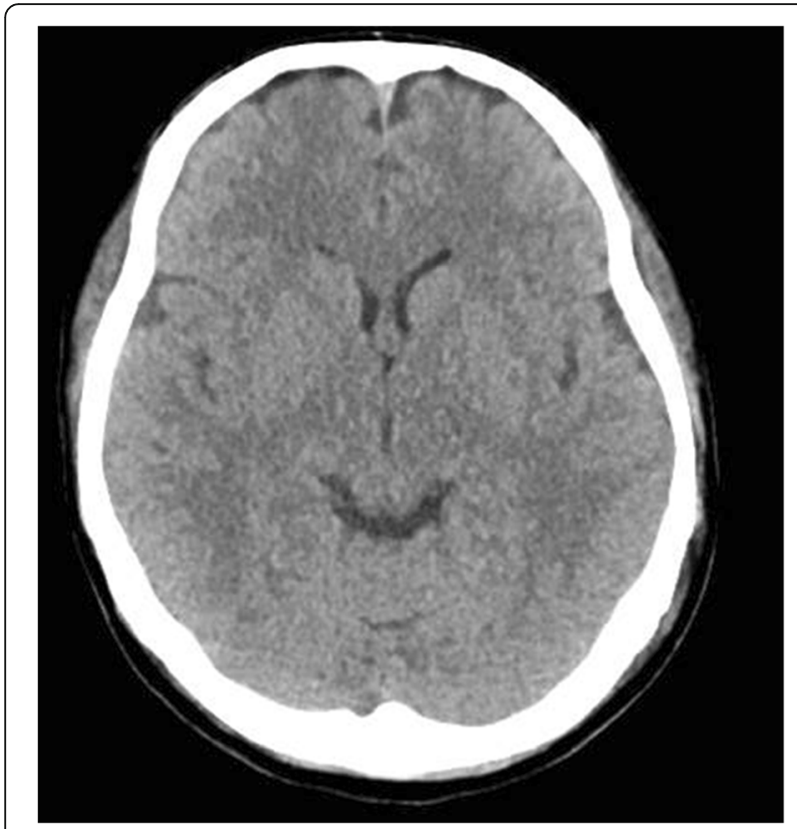

Fig. 3 Head computed tomography immediately after the seizure attack. The image demonstrates mild cerebral edema $7 \mathrm{~h}$ after ICU admission

previous study examined the relationship between the type of submucous leiomyoma and fluid absorption volume [3]. Type 0,1 , or 2 myoma (no, $<50 \%$, or $\geq 50 \%$ myometrial extension, respectively [9]) resulted in mean absorption volume of 450 (range: $0-1700), 957$ (0$3000)$, or $1682(50-4500) \mathrm{mL}$ over 36,47 , or $56 \mathrm{~min}$ of the operation time, respectively. The result has shown a strong relationship between the absorption volume and the operation time. The interruption of the surgery should be considered with the assessment of the difference between the volume of inflow and outflow fluid [2]. In our case, an indication for the interruption was the operation time extended beyond $1 \mathrm{~h}$ with a large difference between inflow and outflow, although the estimation of the absorption volume was difficult because of the substantial spillage. A rapid termination of the operation is recommended after a fluid loss $>1500 \mathrm{~mL}$, and the operation should be interrupted with a loss $>2000$ $\mathrm{mL}$ [3]. Another criteria for interruption may be plasma sodium level $<120 \mathrm{mmol} / \mathrm{L}$ indicating severe hyponatremia $[8]$.

Treatment of severe acute hyponatremia should be considered. A guideline proposes a treatment strategy for hyponatremia with severe symptoms (1D and 2D indicate strong and weak recommendations with low evidence) [10]. Briefly, intravenous infusion of $150 \mathrm{ml} \mathrm{3 \%}$ hypertonic saline over $20 \mathrm{~min}$ (1D), and repeated infusion of the same solution twice until $5 \mathrm{mmol} / \mathrm{L}$ increase of $\mathrm{Na}$, is observed in the first hour (2D). In a case without improvement of symptoms after $5 \mathrm{mmol} / \mathrm{L}$ increase,
3\% hypertonic saline infusion or a continuous hypertonic saline infusion, aiming for $1 \mathrm{mmol} / \mathrm{L}$ increase per hour until the improvement of the symptoms, or increase of plasma sodium level $10 \mathrm{mmol} / \mathrm{L}$ in total, or recovery to $\mathrm{Na} 130 \mathrm{mmol} / \mathrm{L}$ (1D). In our case, plasma sodium level gradually increased since the ICU admission with a treatment of $1.5 \%$ saline started at $5 \mathrm{~h}$ after the admission, seizures, and mild brain edema developed at $7 \mathrm{~h}$ after the admission (Fig. 3). Sodium correction at a higher rate might have been better to avoid these symptoms. Overly rapid correction of hyponatremia can develop osmotic demyelination, where neurological findings improve in the early phase but are followed by a new progression of, sometimes permanent neurological deficits in one to several days later [11]. We treated hyponatremia with a mild increase in plasma sodium level and the patients fully recovered on postoperative day 2 .

Electrolyte-free 3\% d-sorbitol solution was used in this case for the monopolar electrical system. Nowadays, isotonic fluid is also used in hysteroscopic surgery to avoid dilutional hyponatremia. However, cases have been reported that isotonic fluid can result in severe hypokalemia and metabolic acidosis with arrhythmia [12] or severe hyperchloremic acidosis within $30 \mathrm{~min}$ into the surgery [13]. Regardless of the fluid type for uterine distension, fluid balance monitoring is principal in the anesthesia management. One limitation of this report is the lack of the detailed irrigation fluid balance.

As the significant edema and the difference between the fluid inflow and outflow indicated the absorption of irrigation fluid, we administered furosemide to excrete water from the body. It should be noted that chronic furosemide intake can develop hyponatremia $[11,14]$ due to the inhibition of sodium absorption in the kidney.

We experienced severe hyponatremia with a postoperative seizure attack and mild brain edema in a case undergoing a 2-h hysteroscopic procedure with electrolyte-free solution as irrigation fluid. During the surgery, it is essential to monitor the fluid balance closely, and the interruption of the surgery should be considered by prolonged surgery and a large difference between inflow and outflow fluid. Under general anesthesia, caution should be exercised because the typical symptoms of hyponatremia such as nausea and confusion are blinded. Hyponatremia was treated with hypertonic saline administration and left no permanent neurological deficits.

\section{Abbreviations}

ICU: Intensive care unit

Acknowledgements

Not applicable. 


\section{Authors' contributions}

HO This author collected and interpreted the data and drafted the manuscript. NM This author collected and interpreted the data, and drafted and revised the manuscript. RM This author acquisition and interpretation of data and revised the manuscript. YK This author interpreted the data and revised the manuscript with English language assistance. KO This author interpreted the data and revised the manuscript. KK This author interpreted the data and revised the manuscript.TI This author interpreted the data and revised the manuscript. KM This author interpreted the data, and drafted and revised the manuscript. The authors approved the final manuscript.

\section{Funding}

This manuscript was supported by the departmental funding of the Department of Anesthesiology, Showa University School of Medicine, Tokyo 142-8666, Japan.

\section{Availability of data and materials}

Not applicable.

\section{Ethics approval and consent to participate}

The institutional review board approval was waived as this is a single care report.

\section{Consent for publication}

Written informed consent was obtained from the patient.

\section{Competing interests}

Kenichi Masui is an Editor of the Journal of Anesthesia and an associate editorial board member of the British Journal of Anaesthesia. The other authors declare that they have no competing interests.

\section{Author details}

'Department of Anesthesiology, Showa University School of Medicine, 1-5-8 Hatanodai, Shinagawa, Tokyo 142-8666, Japan. ${ }^{2}$ Department of Intensive Care Medicine, Showa University School of Medicine, Tokyo 142-8666, Japan. ${ }^{3}$ Department of Obstetrics and Gynecology, Showa University School of Medicine, Tokyo 142-8666, Japan.

Received: 12 September 2020 Revised: 22 September 2020 Accepted: 24 September 2020 Published online: 01 October 2020

\section{References}

1. McGurgan PM, Mcllwaine P. Complications of hysteroscopy and how to avoid them. Best Pract Res Cl Ob. 2015:29:982-93.

2. Di Spiezio SA, Mazzon I, Bramante S, Bettocchi S, Bifulco G, Guida M, et al. Hysteroscopic myomectomy: a comprehensive review of surgical techniques. Hum Reprod Update. 2007;14:101-19.

3. Emanuel MH, Hart A, Wamsteker K, Lammes F. An analysis of fluid loss during transcervical resection of submucous myomas. Fertil Steril. 1997;68: 881-6.

4. Woo YC, Kang H, Cha SM, Jung YH, Kim JY, Koo GH, et al. Severe intraoperative hyponatremia associated with the absorption of irrigation fluid during hysteroscopic myomectomy: a case report. J Clin Anesth. 2011; 23:649-52

5. Aydeniz B, Gruber IV, Schauf B, Kurek R, Meyer A, Wallwiener D. A multicenter survey of complications associated with 21,676 operative hysteroscopies. Eur J Obstet Gynecol Reprod Biol. 2002;104:160-4.

6. Hepp P, Jüttner T, Beyer I, Fehm T, Janni W, Monaca E. Rapid correction of severe hyponatremia after hysteroscopic surgery - a case report. BMC Anesthesiol. 2015;15:85

7. Witz CA, Silverberg KM, Burns WN, Schenken RS, Olive DL. Complications associated with the absorption of hysteroscopic fluid media. Fertil Steril. 1993:60:745-56.

8. Sterns RH. Disorders of plasma sodium--causes, consequences, and correction. New Engl J Med. 2015;372:55-65

9. Practice Committee of the AAGL. AAGL practice report: practice guidelines for the diagnosis and management of submucous leiomyomas. J Minim Invasive Gynecol. 2012;19:152-71.

10. Spasovski G, Vanholder R, Allolio B, Annane D, Ball S, Bichet D, et al. Clinical practice guideline on diagnosis and treatment of hyponatraemia. Nephrol Dial Transplant. 2014;29:i1-i39.
11. Verbalis JG, Goldsmith SR, Greenberg A, Schrier RW, Sterns RH. Hyponatremia treatment guidelines 2007: expert panel recommendations. Am J Med. 2007;120:S1-S21.

12. Smith CC, P.R. Brown J. A case of cardiac arrhythmia from absorption of normal saline during hysteroscopic myomectomy. J Minim Invasive Gynecol. 2019;26:770-3.

13. Schäfer M, Von Ungern-Sternberg Britta S, Wight E, Schneider Markus C. Isotonic fluid absorption during hysteroscopy resulting in severe hyperchloremic acidosis. Anesthesiology. 2005;103:203-4.

14. Sonnenblick M, Friedlander $Y$, Rosin AJ. Diuretic-induced severe hyponatremia: review and analysis of 129 reported patients. Chest. 1993;103: 601-6.

\section{Publisher's Note}

Springer Nature remains neutral with regard to jurisdictional claims in published maps and institutional affiliations.

\section{Submit your manuscript to a SpringerOpen ${ }^{\circ}$ journal and benefit from:}

- Convenient online submission

- Rigorous peer review

- Open access: articles freely available online

- High visibility within the field

- Retaining the copyright to your article

Submit your next manuscript at $\boldsymbol{\nabla}$ springeropen.com 